$\begin{array}{ll}\text { Research Square } & \begin{array}{l}\text { Preprints are preliminary reports that have not undergone peer review. } \\ \text { They should not be considered conclusive, used to inform clinical practice, } \\ \text { or referenced by the media as validated information. }\end{array}\end{array}$

\title{
Intestinal parasites and human immuno virus in Ethiopian tuberclosis patients: A Systematic review and meta-analysis.
}

Getenet Dessie ( $\square$ ayalew.d16@gmail.com)

Bahir Dar University

Fasil Wagnew

Debre Markos University

Dessalegn Amare

Bahir Dar University

Balew Zeleke

Bahir Dar University

Ayenew Negesse

Debre Markos University

Henok Mulugeta

Debre Markos University

Berhanu Abebaw

Bahir Dar University

Dessalegn Haile

Debre Markos university

Tesfa Dejenie Habtewold

University of groningen

Research article

Keywords: Ethiopia; intestinal parasite; tuberculosis; HIV/AIDS

Posted Date: June 5th, 2019

DOI: https://doi.org/10.21203/rs.2.10099/v1

License: @ (i) This work is licensed under a Creative Commons Attribution 4.0 International License. Read Full License

Version of Record: A version of this preprint was published at Current Therapeutic Research on January 1st, 2020. See the published version at https://doi.org/10.1016/j.curtheres.2020.100603. 


\section{Abstract}

Background: The distribution of intestinal parasites among patients with tuberculosis in Ethiopia has not been well understood. Thus, this systematic review and meta-analysis was designed to determine the pooled national prevalence of intestinal parasites and its association with HIV among patients with tuberculosis in Ethiopia. Methods: Original articles were searched in PubMed, Google Scholar, EMBASE, and World Health Organization's HINARI portal and supplemented by the hand searching of cross-references. Data were extracted using a standard data extraction checklist. Random-effects model was used to estimate the pooled prevalence of intestinal parasites and odds ratio of the association. The 12 statistic was utilized to quantify statistical heterogeneity across studies. Funnel plot asymmetry and Egger's regression tests were used to check for publication bias. The analysis was done by STATA version 14 for Windows. Results: Of 725 identified studies, 12 articles were eligible for inclusion in the final analysis. The pooled national prevalence of intestinal parasites among patients with tuberculosis in Ethiopia was 36.1\% (95\% Cl: $22.1-50.1$, 12:98.7\%). Subgroup analysis based on study design indicated that the prevalence of intestinal parasite among case-control studies was $41.69 \%$ (95\% Cl: $28.6-54.8,12$ : 95.1\%). The odds of intestinal parasites among patients with tuberculosis- HIV co-infection was not significantly different compared with patients with tuberculosis without HIV/AIDS (OR: 0.99, 95\% Cl: 0.7 - 4.7, p: 0.96). Conclusion: In Ethiopia, at least one out of three patients with tuberculosis have intestinal parasite. These findings suggest the need of more attention on increasing screening tuberculosis patients for intestinal parasites and deworming intervention.

\section{Introduction}

Parasitic and tuberculosis infections are among the most prevalent infections in humans in developing countries (1). The overlap of TB and parasitic disease morbidity presented with high and consistent figures all over the world (2-6). More than half of people with latent or active tuberculosis infections have intestinal parasitic infestation, which are common in high tuberculosis (TB) burden nations ( 7). In Africa, one-third of TB patients have intestinal parasite infection(IPIs) (8) that contribute for high rate of therapeutic failure of pulmonary TB (9).

It is evident that pulmonary tuberculosis and parasitic diseases were shown to be risk factors for each other and represented with high magnitude of comorbidity in developing countries $(8,10)$. Co-infection may significantly inhibit the host's immune system, increase antibacterial therapy intolerance and be detrimental to the prognosis of the disease. In addition, infection with parasitic diseases can alter the protective immune response to mycobacterium tuberculosis. This indicates that concomitant helminthic infections weaken immune resistance to mycobacterial infections ( 11,12$)$. Furthermore, the presence of intestinal parasites affects the effectiveness of vaccine against TB and increases the chance of developing active tuberculosis diseases after vaccination (13).

In addition, parasitic infection presented with more severe radiological pulmonary disease in the number of involved lung zones at the end of TB treatment course. In particular, simultaneous intestinal helminth infection in patients with newly diagnosed TB alters patient's immunity profile that could favor persistent MTB infection and a more protracted clinical course of the disease $(14,15)$.

In developing countries, parasitic worm infections among TB patients are common and increases the chance for TB complication. Parasitic infection increases the chance of TB lung damage and induces the progression of a latent TB infection to active tuberculosis disease ( 16). The presence of high tuberculosis progression, delay in clinical response and sustained infectiousness leads to high transmission rate of TB to healthy individual (17-19).

There are factors that increase the risk of having parasites infection among TB patients. Personal hygiene, residence, eosinophils count and habit of washing vegetables/fruits are some of the factors that listed in previous studies $(10,20,21)$. On one hand, the presence of immunocompromised diseases, such as HIV/AIDS associated with TB. On the other hand, HIV/AIDS is supposed to be a risk factor for IPIs. Currently, there is high prevalence of TB/HV comorbidity that was estimated to be from $22 \%$ to $25.6 \%$ in Ethiopia (22-24). Parasitic infections represent a major public health problem in immunocompromised individuals (25). Human immunodeficiency virus infection accounts for the highest prevalence of IPIs among TB patients in comparison with TB patients without immunodeficiency (26) while another finding indicate the presence of significantly lower prevalence of IPIs among HIV positive tuberculosis patients ( 2).

In sum, high prevalence of TB and IPIs comorbidity can be explained on the basis of low level of socioeconomic and immunity status(27). Literatures about the prevalence and risk factors of intestinal parasites among these vulnerable populations is an input to policy makers and program planners to have due attention and to take appropriate measures. However, there has been a limited understanding about the extent of parasitosis co-morbidities with tuberculosis in Ethiopia. The available few evidences are inconclusive and inconsistent. Hence, pointing the overall level of comorbidity might alarm policy makers, ministry of health to develop interventional guidelines or bi-directional frameworks for effective treatment of TB and parasite infection comorbidity as well as successful implementation of the national TB control and prevention strategy. Therefore, this systemic review and meta-analysis aimed to determine the pooled national prevalence of intestinal parasites and its association with HIV among patients with tuberculosis in Ethiopia.

\section{Methods}

\section{Search approach and appraisal of studies}

Articles were accessed through web-based electronic database searches, desk reviews of the grey literature, and cross-references of identified studies. The electronic databases searched were PubMed, Google Scholar, EMBASE, and World Health Organization (WHO) database portal for low and middle-income countries that includes the Web of Science, SCOPUS, African Index Medicus (AIM), Cumulative Index to Nursing and Allied Health Literature (CINAHL), WHO's Institutional Repository for Information Sharing (IRIS) and African Journals Online databases. In addition, related articles were obtained through review of the grey literature available on local shelves and from reviewing cross-references of identified articles. 
Searching was done using the following key terms: "intestinal diseases, parasitic", "intestinal", "diseases", "parasitic", "parasitic intestinal diseases", "intestinal", "parasites", "intestinal parasites", intestinal helminthes", "intestinal protozoa", "soil-transmitted helminthes", "tuberculosis", "patients", "Ethiopia". These key terms were combined used "AND" and "OR" Boolean operators. To allow a comprehensive search strategy, these key terms were pre-defined that included all fields within records. Medical Subject Headings (MeSH terms) was also used to help expand the search in advanced PubMed search. The study period for searching of article was conducted from November 10,2018 to February 1, 2019. Endnote citation manager software version X7 for Windows was utilized to collect and organize search outcomes and for removal duplicate articles.

Population $(\mathrm{P})$ : patients with tuberculosis.

Exposure (E): presence of intestinal parasites

Comparison (C): Tuberculosis patients without HIV

Outcome (0): intestinal parasites. The prevalence was measured as the number of subjects with comorbidity of TB/ IPIs in the study divided by the total number of patients in a study multiplied by 100 . We also estimate the association (as measured by crude odds ratios) between comorbidity and patient's HIV status.

\section{Inclusion and exclusion criteria}

All articles for the study were included if they met the following inclusion criteria: written in English-language, full-text articles on observational studies (casecontrol or cross sectional), conducted in Ethiopia from 2004 to 2018, published in peer-reviewed journals or that available at local shelves, and used internationally accepted diagnostic criteria to diagnose intestinal parasite. On the other hand, studies which didn't report specific outcomes for intestinal parasites quantitatively were excluded from the final analysis.

\section{Data abstraction and quality assessment}

After preliminary assessment, two reviewers downloaded abstracts to assess for inclusion. The abstracts were assessed for agreement with the inclusion criteria. When it was unclear whether an abstract was relevant, it was included for retrieval. At this stage articles deemed irrelevant or out of the scope of the study were excluded and the full-text of the rest articles downloaded for a detailed review. Two reviewers then assessed the quality of potentially eligible articles using Newcastle-Ottawa Scale (NOS) criteria (28) that was validated previously(29). There are three main categories for NOS criteria: Selection, Exposure, and Comparability. A study can be awarded a maximum of one star for each numbered item within the selection and exposure categories. A maximum of two stars can be given for comparability categories. Then the number of stars that was given for each numbered item was computed to determine the quality score of each study. Discrepancies in quality assessment scores were resolved with a third reviewer whenever appropriate. The average of two independent reviewer's score was used to determine the quality of each article. The current systematic review and meta-analysis was conducted in accordance with the Preferred Reporting Items for Systematic Reviews and Meta-Analyses Protocol (PRISMA-P) guidelines ( 30).

\section{Data analysis}

Using a Microsoft Excel spreadsheet template that develop based on Joanna Briggs Institute format, author name, publication year, region, dominant parasites, the age-range of patients, and funder were extracted from each study( 31). These data were then imported to Stata version 14 software for Windows to compute the pooled prevalence of intestinal parasites and to examine the association with HIV. The statistical heterogeneity of study outcomes was assessed using the $\mathrm{I}^{2}$ statistics (32). Methodological heterogeneity was evaluated by comparing study design. Additionally, clinical heterogeneity that can arises from differences in participant characteristics (e.g., sex, age, baseline disease severity, ethnicity, comorbidities) and types or timing of outcome measurements was assessed with face-to-face discussion by authors. First, we set and agree on definition of Variations in sex, age, baseline disease severity, ethnicity, comorbidities) and types or timing of outcome measurements. Next, we have discussed and had a consensus about how much this heterogeneity affects our pooled analysis. Random-effects model was used to estimate the pooled prevalence of IPs at a $95 \%$ confidence interval (Cl). Because theoretically we expected that the study settings and socio-economic contexts might differ radically across these studies, subgroup analysis based on study design and group of parasites. We used visual examination of funnel plot asymmetry and Egger's regression tests to check for publication bias ( 33 ). Meta-regression analysis was employed to identify the source of heterogeneity using publication years, sample size and region as covariates. Sensitivity analysis was also performed to examine influence of each study on the overall effect size. We appraised the risk of bias using the 10-item rating scale developed by Hoy et al. for prevalence studies(34). The tool assesses studies on 10 domains, including sampling, data collection, reliability and validity of study tools, case definition, and prevalence periods. Each study was assigned a score of 1 ("yes" answers to domain questions) or 0 ("no" answers to domain questions) for each domain, and these scores were summed to provide an overall study quality score. Scores of 8-10 were considered as having a "low risk of bias", 6-7 a "moderate risk", and 0-5 a "high risk". For the final risk of bias classification, disagreements between the reviewers were resolved via consensus (Additional file 1).

\section{Results}

\section{Identification and description of studies}

Of 725 identified studies, 260 duplicate articles were excluded after reviewing the titles and abstracts. Next, 452 articles were excluded with a reason of irrelevance. Finally, the full-text of the remaining 13 articles were downloaded and assessed for quality and for the presence of all required information. One article was excluded since the outcome was not clearly stated(35). The remaining 11 studies were included in the final meta-analysis (Figure 1).

Figure 1. PRISMA flow diagram showing the procedure of selecting of studies. 


\section{Characteristics of included studies}

Twelve studies with a total sample of 1,927 tuberculosis patients were included. Most of the study participants belonged to the age range of 2-100 years. Eight studies were conducted in Amhara region (36-43), two in Oromia region (44, 45), and two studies in Addis Ababa and SNNPR (20, 21). All studies used direct microscope examination of stool to identify intestinal parasites. Half of the studies were case-control study. The quality score ranges from six to seven with mean score of $6.8(\mathrm{SD}=0.25)$ (Table 1$)$.

\section{Prevalence of intestinal parasite}

Both the lowest (2\%) (43) and highest (40.5\%) (41) prevalence of intestinal parasites were reported in Amhara region. The pooled national prevalence of intestinal parasites among tuberculosis patient in Ethiopia was $36.11 \%$ (95\% Cl: $22.08-50.13,1^{2}$ : $98.7 \%$, p: 0.01) (Figure 2). Visual examination of the funnel plot revealed deviation (Additional file 2). However, both Begg's ( $p=0.27)$ and Egger's tests $(p=0.57)$ of the intercept indicated the absence of significant publication bias.

Figure 2: Pooled prevalence of intestinal parasites among patients with tuberculosis in Ethiopia, 2004 to 2018.

\section{Subgroup and sensitivity analysis}

Based on the subgroup analysis, the pooled prevalence of intestinal parasites among case-control studies was $41.69 \%\left(95 \% \mathrm{Cl}: 28.57-54.81\right.$, p: $0.01, \mathrm{I}^{2}$ :95.1\%) and $30.45 \%$ (95\% Cl: $11.66-49.24$, p: $0.01, \mathrm{I}^{2}$ :) in cross-sectional studies (Figure 3).

Figure 3: Intestinal parasites based on study design among patients with tuberculosis in Ethiopia, 2004 to 2018.

Additionally, subgroup analysis based on types of intestinal parasites showed that the highest percentage was reported for helminths specious with a prevalence of $43.3 \%\left(95 \% \mathrm{Cl}: 30.4 \%-56.3 \%, \mathrm{I}^{2}: 93.7 \%\right)$ (Figure 4$)$. The sensitivity analysis showed that none of the studies significantly affected the overall pooled estimate of intestinal parasite.

Figure 4: Intestinal parasites based on category of intestinal parasite among patients with tuberculosis in Ethiopia, 2004 to 2018.

\section{Meta-regression analysis}

The univariate meta-regression analysis, showed that a one person increases of sample size brought a variation on prevalence of each study by $0.2(p=0.03)$ (Table 2).

Six studies $(21,36,37,39,41,42)$ reported the association between HIV status and intestinal parasite. The odds of intestinal parasites among tuberculosis patients with HIV/AIDS was not significantly differed by compared with tuberculosis patients without HIV/AIDS (OR=0.99, 95\% Cl: $0.71-4.71, \mathrm{I}^{2}=41.5 \%, \mathrm{p}=$ 0.13) (Figure 5). Even though the funnel plot showed slight deviation (Additional file 3), Begg's $(p=0.57)$ and Egger's ( $p=0.91)$ test showed the absence of significant publication bias.

Figure 5: Forest plot of six studies examining the effect of HIV sero status on intestinal parasite 2004-2018, Ethiopia.

\section{Discussion}

Tuberculosis and intestinal parasites overlap geographically, and can represented with high prevalence in the area where there is poor socioeconomic status ( 46). Additionally, it is evident that due to complicated immune status of TB patients with immunodeficiency disorders, this group of patients are at higher risk of developing intestinal parasites infection (26). To our knowledge, this is the first meta-analysis in Ethiopia to provide the pooled national prevalence of intestinal parasites and its association with HIV among tuberculosis patients. The national prevalence of intestinal parasites among patients with TB was $36.11 \%$. This finding is consistent with a report in Tanzania with prevalence of $31.8 \%(8)$.

Our finding was high compared to a report in Egypt (16\%)(9) and China (21.7\%) (47). The Egyptian study (9) was only assessed the burden of a single parasite, which was not a dominant parasite in our finding. In our study, Ascaris lumbricoides was the dominant parasite. Thus, high prevalence of Ascaris lumbricoides in our study might increase the overall IPIs prevalence and can be accounted for this variation. Socioeconomic difference between Ethiopia and China can be contributed for this discrepancy. Ethiopia is low-income country whose peoples live under poverty whereby risk factors, such as poor sanitation, low health awareness, low urbanization and low health care service, high burden of parasitosis are evident compared to China (48). In China, the Chinese Center for Disease Control and Prevention provide specialized hospital care for patients with IPIs. The presence of this care unit attributed to the nationwide scale-up of tuberculosis management and National Tuberculosis Control Program. Patients in a specialized care unit have better follow-up, receive appropriate examinations, treatment regimens and rigorous supervision when compared with patients that takes treatment at hospital level (49). Consequently, the burden of IPIs in china might decrease in china (50).

On the other hand, our finding was lower than the study report in brazil (65\%) (7). This difference can be explained by the variation in the study area. Our study estimated the prevalence from studies conducted without consideration of socio-economical class. However, the Brazilian study (7) was conducted among low-income community, in particular in the area where there is inadequate sanitary structure, latrines being shared with other rooms, well water was the main source of drinking, and near to half of families had low income.

Our subgroup analysis result showed that estimate from case-control studies was higher than cross-sectional studies. This difference might happen related to the nature of sample selection. The unique advantage of cross-sectional surveys is that it is possible to determine the prevalence of an outcome because the 
study samples are selected randomly (51). Conversely, in case-control studies, cases and/or controls are selected on criteria related to the exposure of interest that can affect the overall prevalence (52). Based on the category of parasite subgroup analysis, the highest percentage was reported for helminths group with a prevalence of $43.3 \%$. This finding was consistent with previous studies that conducted among people with TB $(2,10)$. However, our finding was totally different from large surveys report on non-TB people in Ethiopia (53), Ghana (54) and Brazil ( 55) with higher proportion of protozoal infection reported than helminths. These evidence can suggest the presence of strong immunological and geographical connection between helminths and TB that contribute for high burden of helminthiases among tuberculosis patients ( $56-58)$.

The present meta-analysis showed that the odds of intestinal parasites among tuberculosis patients was not significantly different in patients with or without HIV. Similarly, previous studies concluded that the presence of HIV could not contribute for high parasitosis among TB patients ( 8,10 ). These might be due to the presence of better follow-up for patients with HIV. Currently, there is better awareness of professionals in adopting prevention and treatment measures against opportunistic infection, such as intestinal parasites in HIV patients. In addition, the current Ethiopian ART guideline recommend anthelminthic for ART patients for deworming purpose ( 59). In the past few years, the presence of appropriate follow-up and treatment for IPIs at ART clinic dramatically decreased the prevalence among HIV patients (60). Moreover, patients might regain their immunity after initiation of ART that can minimize intestinal parasites disease ( 61).

The presence high Helminths infection among patients with TB in our finding implies that these patients are risk for sustained infectiousness that can lead to high transmission rate of TB to healthy individual. This issue directly interfere with the national TB control and prevention strategy( 17). Antigens from helminths and mycobacteria have immunomodulatory activities that can affect immune responses for microbes. There are immunological evidences demonstrating that helminths clearly alter the magnitude of the mycobacteria-specific cytokine responses and the control of the mycobacteria growth. This delays the clinical response of TB patients $(18,19)$.

Ethiopia is one of the country that has high burden of multidrug resistance tuberculosis( 62,63$)$. Timely management of risk factors like intestinal parasitosis can improve the effectiveness of anti-TB treatment and reduce the magnitude of multidrug resistance tuberculosis (MDR-TB). It is known that the effectiveness of anti-TB treatment can greatly have influenced by duration and patient adherence with Anti-TB drugs( 64). Patients with parasitosis comorbidities with tuberculosis presented with difficulty of adherence with anti-tuberculosis treatment and low effectiveness of overall TB therapy. Consequently, it increases the burden of health institution work load, the occurrence of new tuberculosis infection and the national burden of MDR-TB( 11).

In most developing countries where tuberculosis infection is prevalent, parasitic infections are also predominant medical problems( 11). Reducing the burden of these parasites is important to reduce the mortality and morbidity associated with tuberculosis infections. Parasitic infections have profound debilitating effects particularly on the immune system of the host, potently compromising the host capacity to cope with tuberculosis infection and to mount efficacious immune responses. In addition, without the eradication of helminthic parasites, TB treatment would fail to confer protection for new TB infection in tuberculosis endemic areas. Implying that eradication of helminthic infections or modulation of the immune change that they cause, should be instituted prior to the plan of TB zero prevalence in the country. Therefore, de-worming for eradication of helminthic infections throughout the country in the context of tuberculosis epidemics should be seriously considered $(14,65)$.

\section{STUDY STRENGTH AND LIMITATIONS}

The present meta-analysis is the first in Ethiopia that can give nationally pooled evidence about the overall national burden of IPs among patients with TB.

This meta-analysis has also limitations. First, most of the studies reviewed were published in small regional journals making it difficult to gauge the extent of peer-review and quality of studies. However, all included studies passed the quality screening criteria. Second, due to the absence of data, unadjusted odds ratios were used to estimate the effect size of HIV, which prevented us excluding confounding effect of other factors. The findings of this meta-analysis would be best interpreted keeping these analytical limitations and the limitations of the original studies in mind.

\section{Conclusion}

In Ethiopia, at least one out of three patients with tuberculosis have intestinal parasites. These findings suggest the need of more attention on increasing screening tuberculosis patients for intestinal parasites and deworming to reduce its effect on patient's overall health status.

\section{Abbreviations}

Cl: Confidence interval

MTB: Mycobacterium Tuberculosis

NOS: Newcastle-Ottawa Scale

OR: Odds ratio

SNNPR: Southern Nations, Nationalities, and Peoples' Region

TB: Tuberculosis

\section{Declarations}




\section{Data Availability:}

All relevant data are available within the paper

\section{Ethics approval and consent to participate}

Not applicable

\section{Consent for publication}

Not applicable

\section{Competing interests}

The authors have declared that they have no competing interests.

\section{Author contributions}

GD conceived and designed the research protocol. GD, BZ, HM, DA, AN, DH, TD and FW conducted the literature review, data extraction, data analysis, interpreted the results and drafted the manuscript. GD and FW assisted with assessment of quality of included studies. HM, TD and GM assisted in interpretation of results, manuscript revision and language copyediting. All the authors (AN, BZ, GD, GM, FW, HM, DA, DH and TD) were involved in revising and editing the manuscript.

\section{Funding}

No external funding was obtained for this study.

\section{Acknowledgment}

We would like to thank the administrators of Debre Markos University, and Bahir Dar University who indirectly supported this project.

\section{References}

1. Haque R. Human intestinal parasites. Journal of health, population, and nutrition. 2007;25(4):387.

2. Range N, Magnussen P, Mugomela A, Malenganisho W, Changalucha J, Temu M, et al. HIV and parasitic co-infections in tuberculosis patients: a crosssectional study in Mwanza, Tanzania. Annals of Tropical Medicine \& Parasitology. 2007;101(4):343-51.

3. Escobar MA, Saravia NG, Weigle KA. Concurrent mucosal leishmaniasis and pulmonary tuberculosis. Clinical infectious diseases. 1996;23(4):836-7.

4. Delobel P, Launois P, Djossou F, Sainte-Marie D, Pradinaud R. American cutaneous leishmaniasis, lepromatous leprosy, and pulmonary tuberculosis coinfection with downregulation of the T-helper 1 cell response. Clinical infectious diseases. 2003;37(5):628-33.

5. Duboucher C, Farto-Bensasson F, Chéron M, Peltier J-Y, Beaufils F, Périé G. Lymph node infection by Trichomonas tenax: report of a case with co-infection by Mycobacterium tuberculosis. Human pathology. 2000;31(10):1317-21.

6. Torresi J, Sievert W. Hepatosplenic schistosomiasis presenting as granulomatous hepatitis in an immigrant from the Philippines with pulmonary tuberculosis, tuberculous lymphadenitis, and a history of alcohol abuse. Journal of travel medicine. 2001;8(4):216-8.

7. Cardoso BA, Fonseca FdO, Moraes Neto AHAd, Martins ACGS, Oliveira NVdS, Lima LNGC, et al. Environmental aspects related to tuberculosis and intestinal parasites in a low-income community of the Brazilian Amazon. Revista do Instituto de Medicina Tropical de São Paulo. $2017 ; 59$.

8. Mhimbira F, Hella J, Said K, Kamwela L, Sasamalo M, Maroa T, et al. Prevalence and clinical relevance of helminth co-infections among tuberculosis patients in urban Tanzania. PLoS neglected tropical diseases. 2017;11(2):e0005342.

9. Hasanain AFA, Zayed AA-AH, Mahdy RE, Nafee AMA, Attia RA-MH, Mohamed AO. Hookworm infection among patients with pulmonary tuberculosis: Impact of co-infection on the therapeutic failure of pulmonary tuberculosis. International journal of mycobacteriology. 2015;4(4):318-22.

10. Neto L, Oliveira RdVCd, Totino PR, Sant'Anna FM, Coelho VdO, Rolla VC, et al. Enteroparasitosis prevalence and parasitism influence in clinical outcomes of tuberculosis patients with or without HIV co-infection in a reference hospital in Rio de Janeiro (2000-2006). Brazilian Journal of Infectious Diseases.

2009;13(6):427-32.

11. Li X-X, Zhou X-N. Co-infection of tuberculosis and parasitic diseases in humans: a systematic review. Parasites \& vectors. 2013;6(1):79.

12. Elias D, Wolday D, Akuffo H, Petros B, Bronner U, Britton S. Effect of deworming on human T cell responses to mycobacterial antigens in helminth-exposed individuals before and after bacille calmette-guérin (BCG) vaccination. Clinical \& Experimental Immunology. 2001;123(2):219-25.

13. Elias D, Britton S, Kassu A, Akuffo H. Chronic helminth infections may negatively influence immunity against tuberculosis and other diseases of public health importance. Expert review of anti-infective therapy. 2007;5(3):475-84. 
14. Resende Co T, Hirsch CS, Toossi Z, Dietze R, Ribeiro-Rodrigues R. Intestinal helminth co-infection has a negative impact on both anti-Mycobacterium tuberculosis immunity and clinical response to tuberculosis therapy. Clinical \& Experimental Immunology. 2007;147(1):45-52.

15. Mkhize-Kwitshana ZL, Tadokera R, Mabaso MH. Helminthiasis: a systematic review of the immune interactions present in individuals coinfected with HIV and/or tuberculosis. Human Helminthiasis: InTech; 2017.

16. Monin L, Griffiths KL, Lam WY, Gopal R, Kang DD, Ahmed M, et al. Helminth-induced arginase-1 exacerbates lung inflammation and disease severity in tuberculosis. The Journal of clinical investigation. 2015;125(12):4699-713.

17. DiNardo AR, Nishiguchi T, Mace EM, Rajapakshe K, Mtetwa G, Kay A, et al. Schistosomiasis Induces Persistent DNA Methylation and Tuberculosis-Specific Immune Changes. The Journal of Immunology. 2018;201(1):124-33.

18. Feleke BE, Alene GD, Feleke TE, Motebaynore Y, Biadglegne F. Clinical response of tuberculosis patients, a prospective cohort study. PloS one. 2018;13(1):e0190207.

19. Méndez-Samperio P. Immunological mechanisms by which concomitant helminth infections predispose to the development of human tuberculosis. The Korean journal of parasitology. 2012;50(4):281.

20. Alemu A. Intestinal Parasites Co-infection and Associated factors Among Active Pulmonary Tuberculosis Patients in Selected Health Centers, Addis Ababa, Ethiopia: A Case control stud [ Research thesis ]. Addis Ababa Addis Ababa University; 2018.

21. Alemu G, Mama M. Intestinal helminth co-infection and associated factors among tuberculosis patients in Arba Minch, Ethiopia. BMC infectious diseases. 2017;17(1):68.

22. Teweldemedhin M, Asres N, Gebreyesus H, Asgedom SW. Tuberculosis-Human Immunodeficiency Virus (HIV) co-infection in Ethiopia: a systematic review and meta-analysis. BMC infectious diseases. 2018;18(1):676.

23. Tesfaye B, Alebel A, Gebrie A, Zegeye A, Tesema C, Kassie B. The twin epidemics: Prevalence of TB/HIV co-infection and its associated factors in Ethiopia; A systematic review and meta-analysis. PloS one. 2018;13(10):e0203986.

24. Endalamaw A, Ambachew S, Geremew D, Habtewold T. HIV infection and unknown HIV status among tuberculosis patients in Ethiopia: a systematic review and meta-analysis. The International Journal of Tuberculosis and Lung Disease. 2019;23(2):187-94.

25. AK D, Gaber M, Hassan T, El Kady A, Badary D, Mahmoud H. Parasites Associated With Human Immune-Deficiency Virus (Hiv) Infection in Assiut University Hospitals, Egypt. Madridge J Vacc. 2018;2(1):49-54.

26. Taghipour A, Azimi T, Javanmard E, Pormohammad A, Olfatifar M, Rostami A, et al. Immunocompromised patients with Pulmonary Tuberculosis; a susceptible group to Intestinal parasites. Gastroenterology and Hepatology from Bed to Bench. 2018.

27. Gabrie JA, Rueda MM, Rodriguez CA, Canales M, Sanchez AL. Immune Profile of Honduran Schoolchildren with Intestinal Parasites: The Skewed Response against Geohelminths. 2016;2016:1769585.

28. Stang A. Critical evaluation of the Newcastle-Ottawa scale for the assessment of the quality of nonrandomized studies in meta-analyses. European journal of epidemiology. 2010;25(9):603-5.

29. Hartling L, Hamm M, Milne A, Vandermeer B, Santaguida PL, Ansari M, et al. Validity and inter-rater reliability testing of quality assessment instruments. 2012.

30. Moher D, Liberati A, Tetzlaff J, Altman DG. Preferred reporting items for systematic reviews and meta-analyses: the PRISMA statement. Annals of internal medicine. 2009;151(4):264-9.

31. Munn Z, Tufanaru C, Aromataris E. JBI's systematic reviews: data extraction and synthesis. AJN The American Journal of Nursing. 2014;114(7):49-54.

32. Institute JB. Joanna Briggs Institute Reviewers' Manual: 2017 edition. Australia: The Joanna Briggs Institute; 2017. Gaston et al Venous Thromboembolism (VTE) Risk Assessment and Prophylaxis: A Comprehensive Systematic.

33. Huedo-Medina TB, Sánchez-Meca J, Marín-Martínez F, Botella J. Assessing heterogeneity in meta-analysis: Q statistic or I² index? Psychological methods. 2006;11(2):193.

34. Hoy D, Brooks P, Woolf A, Blyth F, March L, Bain C, et al. Assessing risk of bias in prevalence studies: modification of an existing tool and evidence of interrater agreement. Journal of clinical epidemiology. 2012;65(9):934-9.

35. Abate E. The impact of helminth infection in patients with active tuberculosis: Linköping University Electronic Press; 2013.

36. Abate E, Belayneh M, Gelaw A, Idh J, Getachew A, Alemu S, et al. The impact of asymptomatic helminth co-infection in patients with newly diagnosed tuberculosis in north-west Ethiopia. PloS one. 2012;7(8):e42901. 
37. Abate E, Belayneh M, Idh J, Diro E, Elias D, Britton S, et al. Asymptomatic helminth infection in active tuberculosis is associated with increased regulatory and Th-2 responses and a lower sputum smear positivity. PLoS neglected tropical diseases. 2015;9(8):e0003994.

38. Alemayehu M, Birhan W, Belyhun Y, Sahle M, Tessema B. Prevalence of smear positive tuberculosis, intestinal parasites and their co-infection among tuberculosis suspects in Gondar University Hospital and Gondar Poly Clinic, North West Ethiopia. J Microb Biochem Technol. 2014;6(4):179-84.

39. Elias D, Mengistu G, Akuffo H, Britton S. Are intestinal helminths risk factors for developing active tuberculosis? Tropical Medicine \& International Health. 2006;11(4):551-8.

40. Hailu AW. The case control studies of HIV and Intestinal parasitic infections rate in active pulmonary tuberculosis patients in Woldia General Hospital and Health Center in North Wollo, Amhara Region, Ethiopia. International journal of pharma sciences. 2015;5(3):1092.

41. Kassu A, Mengistu G, Ayele B, Diro E, Mekonnen F, Ketema D, et al. HIV and intestinal parasites in adult TB patients in a teaching hospital in Northwest Ethiopia. Tropical doctor. 2007;37(4):222-4.

42. Kassu A, Mohammad A, Fujimaki Y, Moges F, Elias D, Mekonnen F, et al. Serum IgE levels of tuberculosis patients in a tropical setup with high prevalence of HIV and intestinal parasitoses. Clinical \& Experimental Immunology. 2004;138(1):122-7.

43. Tegegne Y, Wondmagegn T, Worku L, Jejaw Zeleke A. Prevalence of Intestinal Parasites and Associated Factors among Pulmonary Tuberculosis Suspected Patients Attending University of Gondar Hospital, Gondar, Northwest Ethiopia. Journal of parasitology research. $2018 ; 2018$.

44. Manuel Ramos J, Reyes F, Tesfamariam A. Intestinal parasites in adults admitted to a rural Ethiopian hospital: Relationship to tuberculosis and malaria. Scandinavian journal of infectious diseases. 2006;38(6-7):460-2.

45. Taha M, Deribew A, Tessema F, Assegid S, Duchateau L, Colebunders R. Risk factors of active tuberculosis in people living with HIV/AIDS in southwest Ethiopia: a case control study. Ethiopian journal of health sciences. 2011;21(2):131-40.

46. Simon GG. Impacts of neglected tropical disease on incidence and progression of HIV/AIDS, tuberculosis, and malaria: scientific links. International Journal of Infectious Diseases. 2016;42:54-7.

47. Disease Control Bureau of the Ministry of Health, National Institute of Parasitic Diseases of the Chinese Center for Disease Control and Prevention .Report on the national survey of current status of major human parasitic diseases in China. Beijing, China: People's Medical Publishing House. . 2008.

48. Hesham M, Edariah A, Norhayati M. Intestinal parasites infections and micronutrient deficiency. Med J Malaysia. $2003 ; 58: 2$.

49. Wang L, Zhang H, Ruan Y, Chin DP, Xia Y, Cheng S, et al. Tuberculosis prevalence in China, 1990-2010; a longitudinal analysis of national survey data. The Lancet. 2014;383(9934):2057-64.

50. Yuan L, Zhang H, Zhou C, Jiang W, Zhao Q, Biao X. Better care provided to patients with tuberculosis at county designated TB hospitals (CTD) compared to non-CTDs in rural China. BMC infectious diseases. 2017;17(1):71.

51. Omair A. Selecting the appropriate study design for your research: Descriptive study designs. Journal of Health Specialties. 2015;3(3):153.

52. Bailey L, Vardulaki K, Langham J, Chandramohan D. Introduction to epidemiology. Black N, Raine R, Eds. London: Open University Press in collaboration with LSHTM; 2006.

53. Hailegebriel T. Prevalence of intestinal parasitic infections and associated risk factors among students at Dona Berber primary school, Bahir Dar, Ethiopia. BMC infectious diseases. 2017;17(1):362.

54. Forson AO, Arthur I, Olu-Taiwo M, Glover KK, Pappoe-Ashong PJ, Ayeh-Kumi PF. Intestinal parasitic infections and risk factors: a cross-sectional survey of some school children in a suburb in Accra, Ghana. BMC research notes. 2017;10(1):485.

55. Seguí R, Muñoz-Antoli C, Klisiowicz DR, Oishi CY, Köster PC, de Lucio A, et al. Prevalence of intestinal parasites, with emphasis on the molecular epidemiology of Giardia duodenalis and Blastocystis sp., in the Paranaguá Bay, Brazil: a community survey. Parasites \& vectors. 2018;11(1):490.

56. Babu S, Nutman TB. Helminth-tuberculosis co-infection: an immunologic perspective. Trends in immunology. 2016;37(9):597-607.

57. Potian JA, Bhatt K, Liu Z, Gause W, Salgame P. Helminthic infection enhances susceptibility to tuberculosis in a murine coinfection model (43.31). Am Assoc Immnol; 2007.

58. Sikalengo G, Hella J, Mhimbira F, Rutaihwa LK, Bani F, Ndege R, et al. Distinct clinical characteristics and helminth co-infections in adult tuberculosis patients from urban compared to rural Tanzania. Infectious diseases of poverty. 2018;7(1):24.

59. Frehiwot N, Mizan K, Seble M, Fethia K, Tekalign M, Zelalem T. National guidelines for comprehensive HIV prevention, care and treatment. Addis Ababa: Ministry of Health. 2014.

60. Missaye A, Dagnew M, Alemu A, Alemu A. Prevalence of intestinal parasites and associated risk factors among HIV/AIDS patients with pre-ART and onART attending dessie hospital ART clinic, Northeast Ethiopia. AIDS research and therapy. 2013;10(1):7. 
61. Cerveja BZ, Tucuzo RM, Madureira AC, Nhacupe N, Langa IA, Buene T, et al. Prevalence of Intestinal Parasites Among HIV Infected and HIV Uninfected Patients Treated at the 1 De Maio Health Centre in Maputo, Mozambique. EC microbiology. 2017;9(6):231.

62. Asgedom SW, Teweldemedhin M, Gebreyesus H. Prevalence of Multidrug-Resistant Tuberculosis and Associated Factors in Ethiopia: A Systematic Review. Journal of pathogens. 2018;2018.

63. Girum T, Muktar E, Lentiro K, Wondiye H, Shewangizaw M. Epidemiology of multidrug-resistant tuberculosis (MDR-TB) in Ethiopia: a systematic review and meta-analysis of the prevalence, determinants and treatment outcome. Tropical Diseases, Travel Medicine and Vaccines. 2018;4(1):5.

64. Alipanah N, Jarlsberg L, Miller C, Linh NN, Falzon D, Jaramillo E, et al. Adherence interventions and outcomes of tuberculosis treatment: A systematic review and meta-analysis of trials and observational studies. PLoS medicine. 2018;15(7):e1002595.

65. Bentwich Z, Horner R, Borkow G. De-worming in developing countries as a feasible and affordable means to fight co-endemic infectious diseases. Open Biology Journal. 2010;3(Special 2):97-103.

\section{Tables}

Table 1: Characteristics of included studies for systematic review and meta-analysis, 2004-2018, Ethiopia. 


\begin{tabular}{|c|c|c|c|c|c|c|c|c|c|}
\hline $\begin{array}{l}\text { Authors } \\
\text { name }\end{array}$ & $\begin{array}{l}\text { Publication } \\
\text { Year }\end{array}$ & Region & $\begin{array}{l}\text { Diagnostic } \\
\text { method for TB }\end{array}$ & $\begin{array}{l}\text { Dominant } \\
\text { parasite }\end{array}$ & Study design & $\begin{array}{l}\text { Age of } \\
\text { subjects }\end{array}$ & $\begin{array}{l}\text { Response } \\
\text { rate(\%) }\end{array}$ & Funding & Prevalence(\%) \\
\hline $\begin{array}{l}\text { A. Kassu et } \\
\text { al(42) }\end{array}$ & 2004 & Amhara & $\begin{array}{l}\text { histopathological } \\
\text { evidence, sputum } \\
\text { smear, } \\
\text { radiographic } \\
\text { examination } \\
\text { consistent with } \\
\text { TB,clinical } \\
\text { response to anti- } \\
\text { TB } \\
\text { chemotherapy. }\end{array}$ & $\begin{array}{l}\text { Ascaris } \\
\text { lumbricoides }\end{array}$ & Crosssectional & $\begin{array}{l}\text { Not } \\
\text { stated }\end{array}$ & $100 \%$ & $\begin{array}{l}\text { Ministry of } \\
\text { Education, } \\
\text { Culture, } \\
\text { Sports, } \\
\text { Science and } \\
\text { Technology } \\
\text { of } \\
\text { Japan,Yakult } \\
\text { Ltd, Japan, } \\
\text { Gondar } \\
\text { university }\end{array}$ & 37.3 \\
\hline $\begin{array}{l}\text { D. Elias et } \\
\text { al(39) }\end{array}$ & 2006 & Amhara & $\begin{array}{l}\text { Sputum smear } \\
\text { microscopy }\end{array}$ & $\begin{array}{l}\text { A. } \\
\text { lumbricoides }\end{array}$ & Case control & $\begin{array}{l}\geq 10 \\
\text { years }\end{array}$ & $73.7 \%$ & $\begin{array}{l}\text { Gondar } \\
\text { University } \\
\text { and } \\
\text { Sida/SAREC }\end{array}$ & 71 \\
\hline $\begin{array}{l}\text { Afework, et } \\
\text { al(41) }\end{array}$ & 2007 & Amhara & $\begin{array}{l}\text { clinical, } \\
\text { radiological, } \\
\text { histopathological } \\
\text { and laboratory } \\
\text { features of the } \\
\text { patients } \\
\text { following } \\
\text { standard } \\
\text { procedures }\end{array}$ & $\begin{array}{l}\text { Ascaris } \\
\text { lumbricoides }\end{array}$ & Crosssectional & $\begin{array}{l}15- \\
80 y e a r s\end{array}$ & $100 \%$ & $\begin{array}{l}\text { University of } \\
\text { Gondar }\end{array}$ & 40.5 \\
\hline $\begin{array}{l}\text { Mohammed } \\
\text { T. et al(45) }\end{array}$ & 2011 & Oromia & Not clearly stated & not stated & Case control & $\geq 15 y e a r s$ & $100 \%$ & $\begin{array}{l}\text { Jimma } \\
\text { University }\end{array}$ & 40.1 \\
\hline $\begin{array}{l}\text { Abate et } \\
\text { al(36) }\end{array}$ & 2012 & Amhara & $\begin{array}{l}\text { Sputum smear, } \\
\text { radiographic } \\
\text { examination }\end{array}$ & $\begin{array}{l}\text { Acaris } \\
\text { lumbricoides }\end{array}$ & Case control & $\begin{array}{l}15-65 \\
\text { years }\end{array}$ & $100 \%$ & Not stated & 29 \\
\hline $\begin{array}{l}\text { Abate et } \\
\text { al(37) }\end{array}$ & 2015 & Amhara & $\begin{array}{l}\text { Sputum smear, } \\
\text { radiographic } \\
\text { examination } \\
\text { consistent with } \\
\text { TB, clinical } \\
\text { response to anti- } \\
\text { TB } \\
\text { chemotherapy. }\end{array}$ & $\begin{array}{l}\text { Ascaris } \\
\text { lumbricoides }\end{array}$ & Case control & $\begin{array}{l}15- \\
60 y e a r s\end{array}$ & $100 \%$ & Not stated & 40 \\
\hline $\begin{array}{l}\text { Hailu et } \\
\text { al(40) }\end{array}$ & 2015 & Amhara & $\begin{array}{l}\text { AFB smear } \\
\text { microscopy }\end{array}$ & not stated & Case control & $\begin{array}{l}18-65 \\
\text { years }\end{array}$ & $100 \%$ & $\begin{array}{l}\text { Hawassa } \\
\text { University }\end{array}$ & 49 \\
\hline $\begin{array}{l}\text { Alemu and } \\
\text { Mama(21) }\end{array}$ & 2017 & SNNPR & $\begin{array}{l}\text { Sputum smear, } \\
\text { radiographic } \\
\text { examination }\end{array}$ & $\begin{array}{l}\text { Ascaris } \\
\text { lumbricoides }\end{array}$ & Crosssectional & $\begin{array}{l}15-65 \\
\text { years }\end{array}$ & $100 \%$ & $\begin{array}{l}\text { Arba Minch } \\
\text { University }\end{array}$ & 26.3 \\
\hline $\begin{array}{l}\text { Alemu et } \\
\text { al(20) }\end{array}$ & 2018 & $\begin{array}{l}\text { Addis } \\
\text { Ababa }\end{array}$ & $\begin{array}{l}\text { Sputum smear, } \\
\text { Xpert MTB/RIF } \\
\text { assay and } \\
\text { culture }\end{array}$ & G.lamblia & Case control & $\begin{array}{l}19- \\
34 \text { years }\end{array}$ & $100 \%$ & $\begin{array}{l}\text { Addis Abeba } \\
\text { University }\end{array}$ & 22 \\
\hline $\begin{array}{l}\text { Tegegne et } \\
\text { al(43) }\end{array}$ & 2018 & Amhara & Sputum smear & $\begin{array}{l}\text { Ascaris } \\
\text { lumbricoides }\end{array}$ & Crosssectional & $\geq 5$ years & $100 \%$ & $\begin{array}{l}\text { University of } \\
\text { Gondar }\end{array}$ & 2 \\
\hline
\end{tabular}

SIDA-Swedish International Development Cooperation Agency.

SAREC-Sustainable Agriculture Research and Extension Center.

Table 2: Meta regression results on selected variables. 


\begin{tabular}{lll} 
Variable & Coefficient & P-value \\
\hline Publication year & -3.9 & 0.06 \\
\hline Sample size & 0.2 & 0.03 \\
\hline Adis Ababa(20) & -19 & 0.51 \\
\hline Amhara $(36-41,43)$ & 4.1 & 0.84 \\
\hline Oromia $(44,45)$ & 8.3 & 0.72 \\
\hline Cross sectional(21, 38, 41-44) & 14.7 & 0.23
\end{tabular}

HIV status and intestinal parasite

\section{Figures}
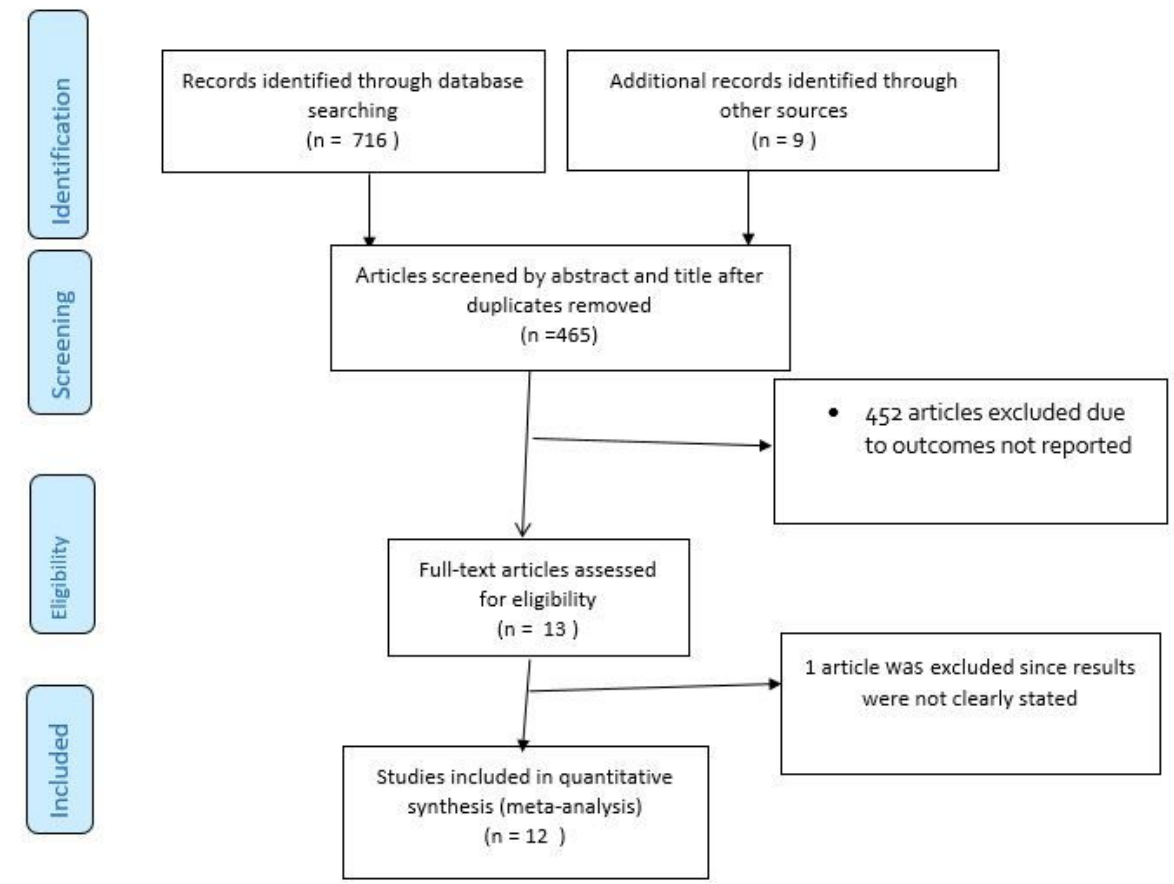

Figure 1

PRISMA flow diagram showing the procedure of selecting of studies.

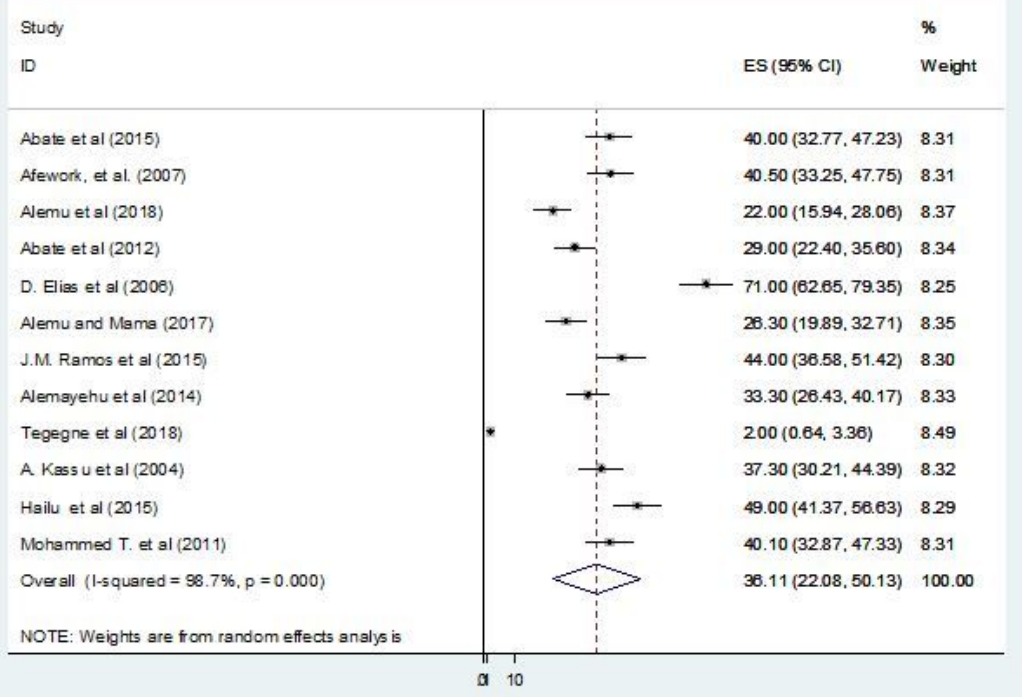

Figure 2

Page $11 / 13$ 
Pooled prevalence of intestinal parasites among patients with tuberculosis in Ethiopia, 2004 to 2018.

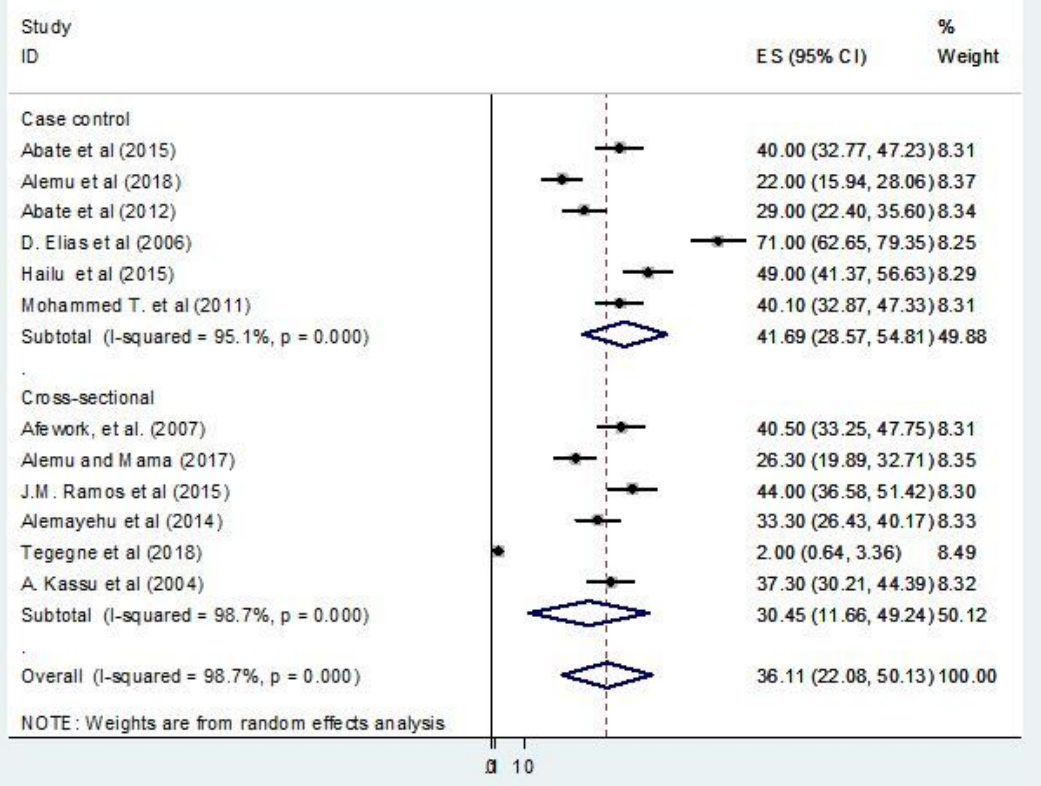

\section{Figure 3}

Intestinal parasites based on study design among patients with tuberculosis in Ethiopia, 2004 to 2018.

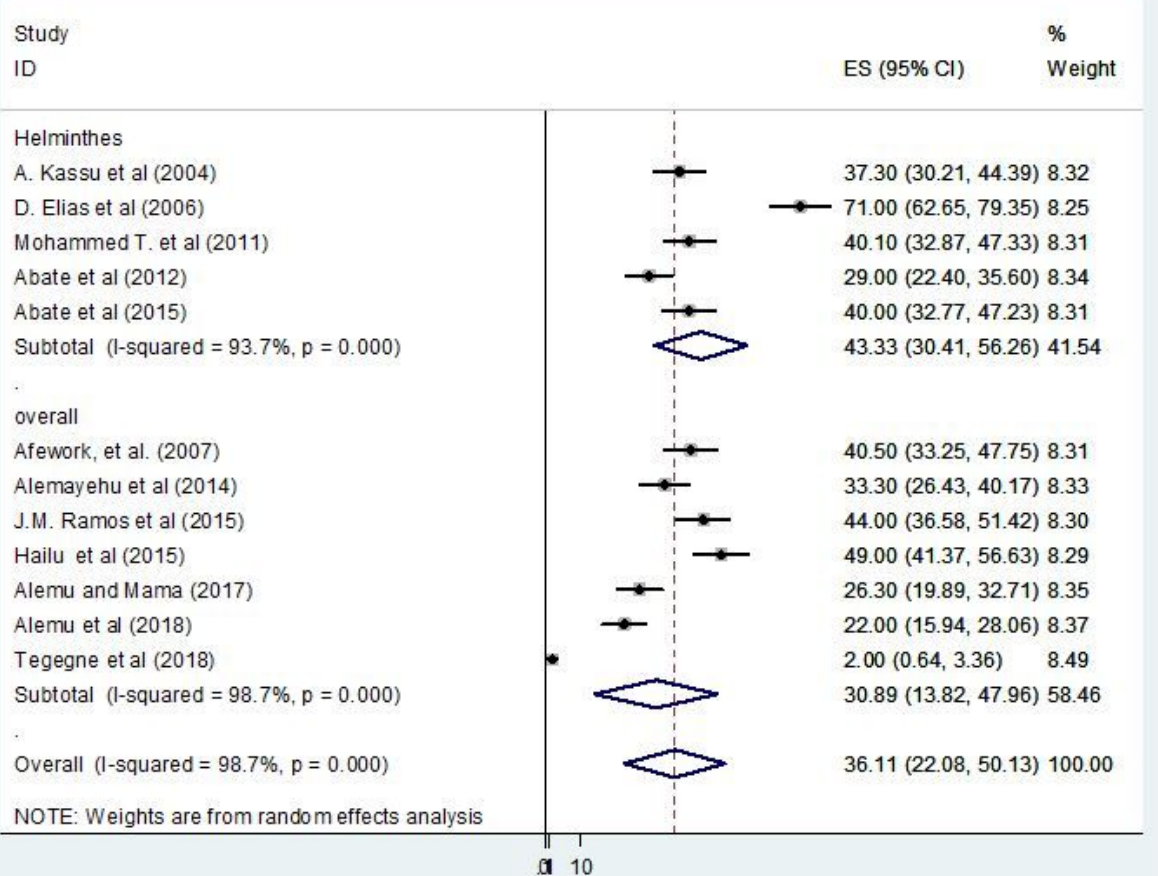

\section{Figure 4}

Intestinal parasites based on category of intestinal parasite among patients with tuberculosis in Ethiopia, 2004 to 2018. 


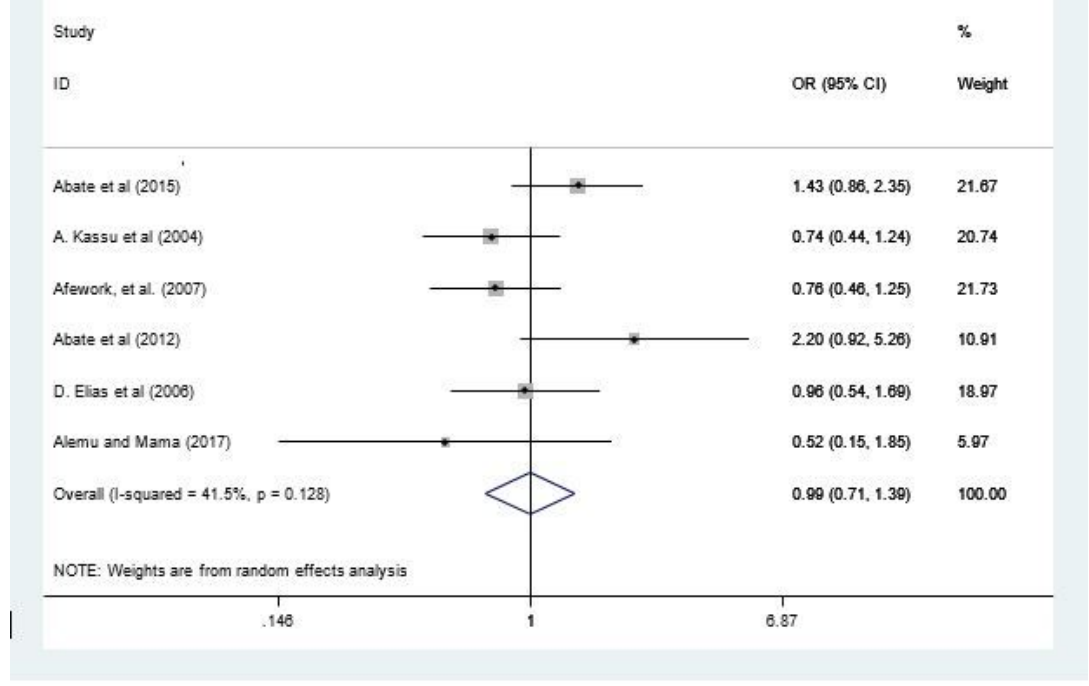

\section{Figure 5}

Forest plot of six studies examining the effect of HIV sero status on intestinal parasite 2004-2018, Ethiopia.

\section{Supplementary Files}

This is a list of supplementary files associated with this preprint. Click to download.

- supplement1.jpg

- supplement2.jpg

- supplement3.pdf 